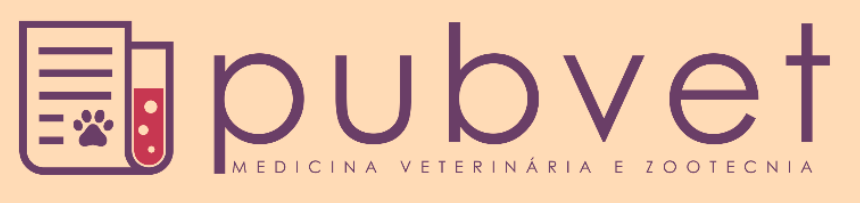

https://doi.org/10.31533/pubvet.v16n02a1036.1-4

\title{
Anomalia de Pelger-Huët em cão (Canis familiaris): Relato de caso
}

\author{
Maritza Nunes Severiano ${ }^{1 *}$, Alexandre Longo Filho ${ }^{1 \bullet}$, Amanda Souto Sarti $^{1 \bullet}$, Danielle \\ Shiguihara $^{10}$, Letícia Burigo Inácio ${ }^{2} \theta$, Thais Jassek Soares ${ }^{10}$ \\ ${ }^{1}$ Médica Veterinária Autônoma. Curitiba - PR, Brasil \\ ${ }^{2}$ Graduanda do curso de Medicina Veterinária da UFPR. Curitiba-PR Brasil. \\ *Autor para correspondência, E-mail: maritzanunes18@gmail.com
}

\begin{abstract}
Resumo. A anomalia de Pelger-Huët é uma alteração genética, que modifica as características morfológicas nucleares dos granulócitos do sistema imune, principalmente em neutrófilos. Essa alteração possui cunho autossômico dominante e apresenta duas possíveis formas, a heterozigota e a homozigota. Objetivou-se relatar a alteração de PelgerHuët em uma cadela, da raça Border Collie, com um ano de idade, que não apresentava sinais clínicos de doença, mas que em hemograma apresentou hipossegmentação de todos os neutrófilos avaliados.
\end{abstract}

Palavras Chaves: Desvio à esquerda, genética, granulócitos, pelger-huët

\section{Pelger Huët anomaly in dog (Canis familiaris): Case report}

Abstract. The Pelger-Huët anomaly is a genetic alteration that modifies the morphological characteristics of the immune system's granulocytes, primarily in neutrophils. This alteration has autosomal dominant characteristic and has two possible forms, heterozygous and homozygous. The aim of this study was to report the Pelger-Huët alteration in a oneyear-old Border Collie female dog, which did not present clinical signs of the disease, but presented hyposegmentation in all neutrophils evaluated in the hemogram.

Keywords: Left shift, genetic, granulocytes, pelger-hüet

\section{Introdução}

A anomalia de Pelger Huët (APH) foi descrita inicialmente em seres humanos (Pelger, 1928) e posteriormente em outros animais. Essa alteração é advinda de uma desordem genética que leva a uma falha da maturação do núcleo durante o desenvolvimento dos granulócitos, evitando assim, que estes tenham segmentações nucleares (Seki et al., 2011).

Essa alteração pode ser observada em esfregaços sanguíneos ao observar núcleos hipossegmentados, ovais ou em formato de amendoim, em basófilos, eosinófilos e principalmente neutrófilos (Seki et al., 2011). Essa visualização pode levar à conclusão errônea de que o animal possui um desvio de neutrófilos à esquerda (DNNE), pois as células da anomalia são confundidas com formas jovens dos granulócitos em questão (Lorenzi, 1992; Thrall, 2015). Essa alteração autossômica dominante, não possui cunho patológico, ou seja, as células continuam atuando normalmente (Xavier, 2015).

A anomalia de Pelger Huët pode ter duas formas em cães: a homozigota e a heterozigota. A forma homozigota é rara e em muitos casos os organismos morrem com pouco tempo de vida (Goulart et al., 2018). Já a forma heterozigota é a mais comum, apresentando a forma clássica da anomalia, ou seja, totalmente assintomática e causando somente a alteração da morfologia nuclear dos granulócitos. 


\section{Relato de caso}

No dia oito de dezembro de 2020 foram analisadas duas amostras de sangue de uma cadela da raça Border Collie, com um ano de idade. Uma das amostras estava acondicionada em um tubo com anticoagulante EDTA, para realizar hemograma e outra em tubo sem anticoagulante com gel separador, para realizar a dosagem de albumina, alanina aminotransferase, bilirrubina total e frações, creatinina, fosfatase alcalina e ureia.

O material veio encaminhado de uma clínica veterinária associada, com o objetivo de realizar exames de rotina do animal. No laboratório, a amostra sem EDTA foi devidamente preparada e desta forma foram realizados o hematócrito, a proteína plasmática, o esfregaço sanguíneo com coloração por panótico rápido e a passagem do sangue pelo equipamento de avaliação hematológica e bioquímica. Nenhum dos dados hematológicos e bioquímicos avaliados pelos aparelhos apresentaram-se alterados.

Em seguida, foi realizada a avaliação microscópica do esfregaço onde não foram constatadas alterações em monócitos, eosinófilos, basófilos e plaquetas, isso comparando com os dados descritos em Santos (2011). Mas, na contagem absoluta de leucócitos foi possível identificar uma leve linfocitose, ausência de neutrófilos segmentados e aumento acentuado de neutrófilos bastonetes (Figura 1), metamielócitos e mielócitos (Tabela 1).

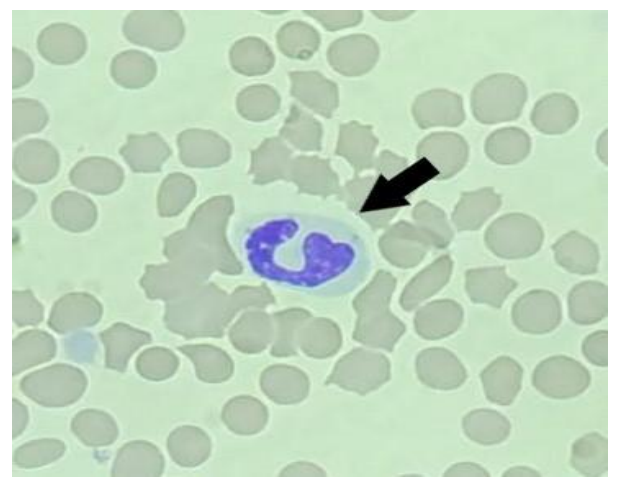

Figura 1. Seta. Neutrófilo hipossegmentado visualizado durante a avaliação microscópica do esfregaço sanguíneo do paciente relatado com Pelger-Huët.

Tabela 1. Resultado do hemograma realizado em 8 de dezembro de 2020, do paciente com a anomalia de Pelger Huët.

\begin{tabular}{lll}
\hline & Resultado & Valor de Referência \\
\hline Eritrócitos & $7,84\left(\times 10^{\wedge} 6\right.$ cels $\left./ \mu \mathrm{L}\right)$ & 5,5 a $8,5\left(\times 10^{\wedge} 6\right.$ cels $\left./ \mu \mathrm{L}\right)$ \\
Hemoglobina & $17,3(\mathrm{~g} / \mathrm{dL})$ & 12 a $18(\mathrm{~g} / \mathrm{dL})$ \\
Hematócrito & $52(\%)$ & 37 a $55(\%)$ \\
VGM & $66,66(\mathrm{fL})$ & 60 a $77(\mathrm{fL})$ \\
CHGM & $33,27(\%)$ & 31 a $36(\%)$ \\
Metarrubrícitos & $0 / 100$ leucócitos & - \\
Proteína Plasmática & $6,6(\mathrm{~g} / \mathrm{dL})$ & 6,0 a $8,0(\mathrm{~g} / \mathrm{dL})$ \\
Leucócitos Totais & $12.100(/ \mu \mathrm{L})$ & 6.000 a $17.000(/ \mu \mathrm{L})$ \\
Neutrófilos Segmentados & $0(/ \mu \mathrm{L})$ & 3.000 a $11.000(/ \mu \mathrm{L})$ \\
Neutrófilos Bastonetes & $3.025(/ \mu \mathrm{L})$ & 0 a $300(/ \mu \mathrm{L})$ \\
Metamielócitos & $2.420(/ \mu \mathrm{L})$ & $0(/ \mu \mathrm{L})$ \\
Mielócitos & $363(/ \mu \mathrm{L})$ & $0(/ \mu \mathrm{L})$ \\
Linfócitos & $5.808(/ \mu \mathrm{L})$ & $1.000 \mathrm{a} 4.800(/ \mu \mathrm{L})$ \\
Monócitos & $363(/ \mu \mathrm{L})$ & 0 a $1.350(/ \mu \mathrm{L})$ \\
Eosinófilos & $121(/ \mu \mathrm{L})$ & 100 a $1.250(/ \mu \mathrm{L})$ \\
Basófilos & $0(/ \mu \mathrm{L})$ & Raros $(/ \mu \mathrm{L})$ \\
Plaquetas & $240.000(/ \mu \mathrm{L})$ & 200.000 a $500.000(/ \mu \mathrm{L})$ \\
\hline
\end{tabular}

As características do exame poderiam levar a um diagnóstico de desvio de neutrófilos à esquerda, mas como o paciente não apresentava alterações clínicas e ausência de critérios de toxicidade neutrofílica (presença de corpúsculo de Dohlë, grânulos tóxicos e/ou vacúolos e basofilia 
citoplasmática) na avaliação do esfregaço sanguíneo, o exame foi lançado com sugestivo da Anomalia de Pelger-Huët.

\section{Discussão}

Existem algumas alterações genéticas que modificam as células sanguíneas e uma delas é a anomalia de Pelger Huët (APH). Essa anormalidade foi descrita em seres humanos, cães, gatos, coelhos e equinos, sendo o primeiro relato ocorrido em 1928 em um humano (Ávila et al., 2009).

Na medicina veterinária o primeiro relato ocorreu em 1955 em cães, seguido de relatos em gatos em 1985 e relato em cavalos a partir de 2006. No primeiro relato felino, essa alteração só foi diagnosticada após confirmar a ausência de doença clínica e infecção mediante realização de leucogramas repetidos em um período de 10 meses (Carper, 1966; Gill et al., 2006; Seki et al., 2011). Essa anomalia se deve a um defeito genético no receptor da lâmina-B (RLB) no cromossomo 1q, sendo conhecido também como laminopatia. A regulação da síntese do material genético e organização da cromatina se deve a RBL que é uma proteína do envelope nuclear, quando a mesma está em $50 \%$ da quantidade normalmente leva à mutação, que resulta na hipossegmentação (Seki et al., 2011).

A APH apresenta duas formas, a homozigota e a heterozigota. A configuração homozigota os núcleos são majoritariamente arredondados, acabam não passando de duas lobulações e apresentam a cromatina densa ao redor do núcleo, mas é rara, e em muitos casos os indivíduos morrem durante a gestação, no parto ou pouco tempo depois do nascimento. Já a forma heterozigota é a mais comum tanto em animais quanto nos seres humanos e sua apresentação é caracterizada por leucócitos granulares com alteração de cromatina e hipossegmentação nuclear (Goulart et al., 2018).

As células com essa alteração genética têm suas funções normais, entretanto, existem algumas diferenças descritas. Essas variações que ocorrem são: a diminuição de células de origem B em cães, células imaturas da APH fagocitando menos que neutrófilos imaturos, ao transfundir o sangue de um animal com a anomalia em um cão normal, os neutrófilos e eosinófilos apresentam uma vida menor, apesar que esse estudo aconteceu somente em um animal, o núcleo hipossegmentado apresenta fissuras nucleares e a heterocromatina é grosseira. Sendo essas duas últimas diferenças bem visíveis em microscopia de varredura (Wilson, 1985).

Para a APH existe um diferencial bem importante, chamado de pseudo APH adquirida, que ocorre quando o organismo é desafiado de alguma forma e os leucócitos granulares são liberados na corrente sanguínea com alterações morfológicas e em sua forma imatura, também chamado de desvio nuclear de neutrófilos à esquerda. A diferenciação morfológica nuclear da alteração hereditária e adquirida não é viável, mas ao pensar na pseudo APH o animal poderá apresentar toxicidade e terá outras afecções como leucemias mieloides, infecções importantes, neoplasias metastáticas na medula óssea e histórico de tratamento medicamentoso, utilizando fármacos que afetam a produção desses granulócitos (Delieu et al., 2006).

O desvio nuclear de neutrófilos à esquerda consiste em um aumento de células jovens na corrente sanguínea, como os bastonetes (Figura 2), metamielocitos e outras formas ainda mais jovens, podendo ser: ordenadamente, com decrescimento da quantidade das células, de acordo com sua jovialidade; ou desordenadamente, quando células mais jovens estão em maiores quantidades que as mais maduras. A produção e liberação desses granulócitos é modificada quando as células estão em grande atividade e em alto uso. A neutropoese acelerada ocorre quando o organismo enfrenta quadros infecciosos severos, onde a produção não é suficiente e são "recrutadas" as formas mais imaturas de neutrófilos ou quando a produção está diminuída, ou alterada, como no uso de fármacos, como sulfonamida, colchicina e o haloperidol e em processos neoplásicos na medula óssea (Delieu et al., 2006; Thrall, 2015).

Desta forma, para diagnosticar a APH é necessário identificar as alterações morfológicas nucleares, onde deve haver mais de 69\% de neutrófilos hipolobulados (Ávila et al., 2009). A pseudo APH deve ser descartada, utilizando a clínica do animal e observando a ausência de toxicidade celular: corpúsculo de Dohlë, grânulos tóxicos e vacúolos. Há também a possibilidade de realizar a avaliação de herança parental da anomalia, realizar repetições de exames para avaliar a continuidade da hipolobulação e se viável coletar a medula óssea para identificar a ausência de neutrófilos segmentados (Goulart et al., 2018). 


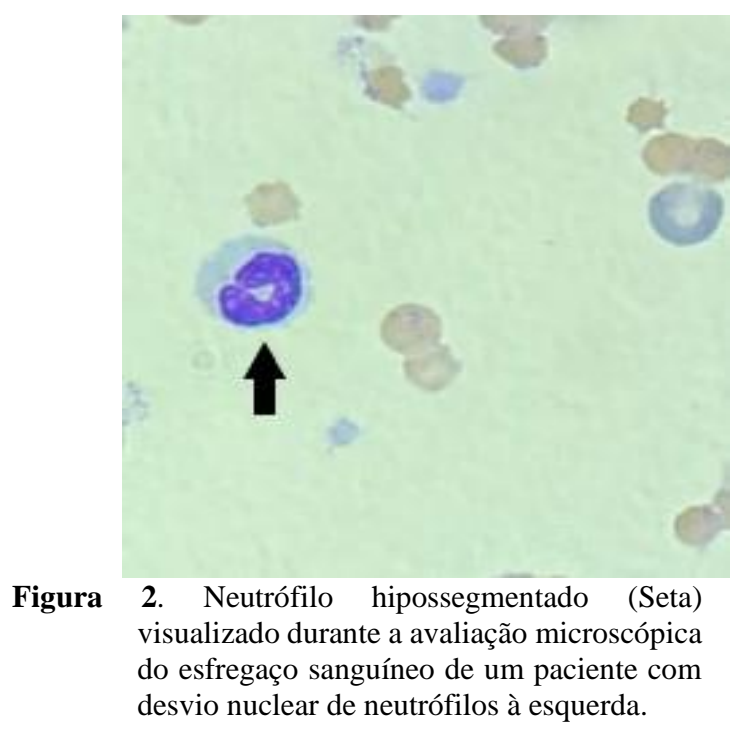

\section{Conclusão}

A relevância dessa alteração, do presente relato, cabe principalmente no papel de diagnóstico diferencial para o desvio nuclear de neutrófilos à esquerda, pois, as patologias que causam esse desvio têm um fator prognóstico reservado a ruim e a anomalia genética possui um prognóstico bom, por ser uma alteração não patológica, levando a diferentes condutas da medicina veterinária clínica.

\section{Referências bibliográficas}

Ávila, D. F., Silva, C. B., Castro, J. R., Rodrigues, C. G., Braga, P. F. S., Mundim, E. D., Mendon, C. S., \& Mundim, A. V. (2009). Anomalia de Pelger-Huët em cadela - Relato de caso. Veterinária Notícias, 15(2), 19-26.

Carper, H. A. (1966). The intravascular survival of transfused canine Pelger-Huet neutrophils and eosinophils. Blood, 27(5), 739-743. https://doi.org/10.1182/blood.V27.5.739.739 .

Delieu, J. M., Horobin, R. W., \& Duguid, J. K. (2006). Formation of immature neutrophil leucocytes in schizophrenic patients treated with various antipsychotic drugs: comparisons and predictions. Journal of Psychopharmacology, 20(6), 824-828. https://doi.org/10.1177/0269881106061112

Gill, A. F., Gaunt, S., \& Sirninger, J. (2006). Congenital Pelger-Huët anomaly in a horse. Veterinary Clinical Pathology, 35(4), 460-462. https://doi.org/10.1111/j.1939-165X.2006.tb00165.x.

Goulart, J. C., Marcusso, P. F., Pereira Júnior, O. C. M., \& Conti, J. B. (2018). Forma heterozigota da anomalia de Pelger-Huët em cão. Acta Scientiae Veterinariae, 46, 5. https://doi.org/10.22456/16799216.86536.

Lorenzi, T. F. (1992). Manual de hematologia: propedêutica e clínica (Vol. 1). Guanabara - Koogan.

Pelger, K. (1928). Demonstrate van een paar zeldzaam voorkomende typen van bloedlichaampjes en bespreking der patienten. Ned Tijdschr Geneeskd, 72(1), 1178.

Santos, L. C. (2011). Laboratório Ambiental. Edunioeste.

Seki, M. C., Anai, L. A., Rosato, P. N., \& Santana, A. E. (2011). Anomalia de Pelger Huet em animais domésticos: uma revisão. Científica Ciências Biológicas e Da Saúde, 13(1), 343-347.

Thrall, M. A. (2015). Hematologia e Bioquímica Clínica Veterinária. In 2. ed. Editora Roca.

Wilson, E. A. (1985). Pelger Huët anomaly in a dog. Canine Practice, 12(2), 39-42.

Xavier, J. L. P. (2015). Anomalia de Pelger-Huët: Revisão da literatura. Visão Acadêmica, 16(3), 53-63.

Histórico do artigo:

Recebido: 8 de outubro de 2021

Aprovado: 7 de novembro de 2021

Disponível online: 23 de fevereiro de 2022
Licenciamento: Este artigo é publicado na modalidade Acesso Aberto sob a licença Creative Commons Atribuição 4.0 (CC-BY 4.0), a qual permite uso irrestrito, distribuição, reprodução em qualquer meio, desde que o autor e a fonte sejam devidamente creditados. 